Article

\title{
Seasonal Trends and Diel Patterns of Downsweep and SEP Calls in Chilean Blue Whales
}

\author{
Laura Redaelli $^{1, *(D)}$, Sari Mangia Woods ${ }^{1}$ (D) , Rafaela Landea ${ }^{2}$ and Laela Sayigh ${ }^{3,4}$ \\ 1 Groningen Institute for Evolutionary Life Sciences, University of Groningen, P.O. Box 11103, \\ 9700 CC Groningen, The Netherlands; sari.mangia@gmail.com \\ 2 Centinela Patagonia, Castro 5700289, Chiloe, Chile; rafaela.landea@gmail.com \\ 3 Biology Department, Woods Hole Oceanographic Institution, Woods Hole, MA 02543, USA; \\ lsayigh@whoi.edu \\ 4 School of Cognitive Science, Hampshire College, Amherst, MA 01002, USA \\ * Correspondence: laura.redaelli.95@gmail.com
}

check for updates

Citation: Redaelli, L.; Mangia Woods, S.; Landea, R.; Sayigh, L. Seasonal Trends and Diel Patterns of Downsweep and SEP Calls in Chilean Blue Whales. J. Mar. Sci. Eng. 2022, 10, 316. https://doi.org/10.3390/ jmse10030316

Academic Editor: Roberto Carlucci

Received: 15 January 2022

Accepted: 21 February 2022

Published: 23 February 2022

Publisher's Note: MDPI stays neutral with regard to jurisdictional claims in published maps and institutional affiliations.

Copyright: (c) 2022 by the authors. Licensee MDPI, Basel, Switzerland. This article is an open access article distributed under the terms and conditions of the Creative Commons Attribution (CC BY) license (https:// creativecommons.org/licenses/by/ $4.0 /)$.

\begin{abstract}
To learn more about the occurrence and behaviour of a recently discovered population of blue whales, passive acoustic data were collected between January 2012 and April 2013 in the Chiloense ecoregion of southern Chile. Automatic detectors and manual auditing were used to detect blue whale songs (SEP calls) and D calls, which were then analysed to gain insights into temporal calling patterns. We found that $\mathrm{D}$ call rates were extremely low during winter (June-August) but gradually increased in spring and summer, decreasing again later during fall. SEP calls were absent for most winter and spring months (July-November) but increased in summer and fall, peaking between March and April. Thus, our results support previous studies documenting the austral summer residency of blue whales in this region, while suggesting that some individuals stay longer, highlighting the importance of this area as a blue whale habitat. We also investigated the daily occurrence of each call type and found that D calls occurred more frequently during dusk and night hours compared to dawn and day periods, whereas SEP calls did not show any significant diel patterns. Overall, these findings help to understand the occurrence and behaviour of endangered Chilean blue whales, enhancing our ability to develop conservation strategies in this important Southern Hemisphere habitat.
\end{abstract}

Keywords: Chilean blue whales; marine bioacoustics; Balaenoptera musculus chilensis; Chile; D calls; SEP calls; diel patterns; seasonal trends; marine conservation

\section{Introduction}

Cetaceans rely heavily on acoustic communication, which allows researchers to study their occurrence and behaviour from a distance. Passive acoustic monitoring (PAM) can be a powerful tool to study cetacean populations over various spatial and temporal scales [1,2]. Furthermore, PAM allows us to study animals without interfering with their behaviour [3].

Diel and seasonal variation in call production occur in a wide variety of marine animals and may be correlated with different behaviours [4,5]. Diel patterning may be caused by sleep or resting, tidal or lunar influences, or prey migrations [6]. A range of diel patterns can be seen among cetacean species. Some odontocetes, such as common dolphins (Delphinus delphis) and harbour porpoises (Phocoena phocoena), are more vocal at night while feeding at depth [5,7], while baleen whales are known to call more during the day (sei whales, Balaenoptera borealis) [8], or twilight hours (Chilean/Peruvian right whales, Eubalaena australis) [9], and Californian blue whales, Balaenoptera musculus) [10], when likely not foraging. Seasonal patterns can provide information on the general presence in an area and migratory movements. Oestreich et al. [11] used song production rate to link the individual and population-level behaviour of blue whales in California. Combining passive acoustic and tag data, the authors identified a temporal acoustic signature of a behavioural 
transition from foraging to migrating. These findings highlight the effectiveness of acoustic studies to understand the behaviour and movements of an endangered species, and to thus identify when and where conservation efforts would be the most effective.

Extensive exploitation during industrial whaling days reduced the populations of blue whales in the Southern Hemisphere to less than $3 \%$ of original numbers [12]. Since legal protection from whaling, some blue whale stocks have shown signs of recovery while others still lack data to determine their status. North Pacific stocks are labelled as 'Low risk: conservation dependent', North Atlantic stocks as 'Vulnerable', Antarctic stocks as 'Critically Endangered', and pygmy blue whales are 'Data Deficient' [13]. Currently, one of the main concerns for coastal marine mammals is loss of critical habitats, such as feeding, breeding, and nursing grounds, due to human activities and climate change [14]. Hucke-Gaete et al. [15] discovered an important coastal blue whale feeding and nursing ground in the Chiloe-Corcovado region in Chilean Patagonia; a subsequent photo-identification study documented between 570 and 762 individuals during one austral summer [16]. Although blue whales in Chilean waters were previously classified as either pygmy (B. m. brevicauda) or Antarctic blue whales (B. m. intermedia) [17,18], a recent study [19] comparing anatomical, genetic, and morphometric evidence [20-22] proposed that they represent a different subspecies, B. m. chilensis, and are thus referred to as 'Chilean blue whales'. Our study examines passive acoustic data in an effort to learn more about Chilean blue whales and to inform the conservation efforts.

Blue whales produce sounds with frequencies among the lowest $(16-100 \mathrm{~Hz})$ and loudest (176.8-188.5 $\mathrm{dB}$ re $1 \mathrm{uPa})$ in the ocean, capable of propagating over extremely long distances $[23,24]$. Blue whales in different geographic areas produce different song patterns, consisting of repeated sequences of 'phrases' made up of recurring pulsed sounds or 'units' [25], which are thought to function as a reproductive display [25-27]. Blue whale songs have usually been attributed to males [25,28,29] and have been reported to occur along entire migratory routes, from summer feeding areas to winter breeding grounds [30-32]. Different song types are typically characterized by differences in unit characteristics (frequency, duration, modulation, inter-unit time intervals), ordering of song units within each phrase (song phrasing), and song phrase duration [25,27,33,34]. Chilean blue whales produce SEP (Southeast Pacific) song types [27]. In the Chiloense Ecoregion the SEP1 song type, which consists of three units, was first recorded in 1971 $(\mathrm{A}-\mathrm{B}-\mathrm{C}$ phrasing, total duration $=36.5 \mathrm{~s}$ ) [35]. More recently, a four-unit song type with a longer duration, called SEP2, has been found to occur more often than SEP1 (A-BC-D phrasing, total duration $=60 \mathrm{~s}$; Figure 1B) [27]. Similar to changes seen in other blue whale populations [31,36-41], both SEP call types showed a declining trend in peak frequency and pulse rate over the span of decades, likely due to sexual selection and cultural conformity [42]. Moreover, recent evidence [11] suggests that song production might have a role in collective migration to mating grounds, helping dispersed populations to appropriately sense and respond to environmental information.

All blue whale populations also produce so-called D calls, downsweeping sounds that are produced by both sexes and that occur in irregular patterns [28] (see examples in Figure 1A). D calls have been suggested to be contact calls, akin to up-calls of right whales and downsweep calls of fin whales, which may be used to locate conspecifics and maintain group cohesion on feeding grounds [26]. However, a recent study [43] reported extensive use of $\mathrm{D}$ calls during competitive male-male behaviour in a reproductive context. D calls have been proposed to occur as counter-calls among multiple whales, as they sometimes occur in overlapping pairs, each produced by a different animal $[26,43]$. Oleson et al. [26] proposed that D calls are unlikely to facilitate prey capture as they are not used to cooperatively herd prey or coordinate underwater activity during feeding, such as the feeding cries of humpback whales do. In fact, Oleson et al. [26,28] found that D calls were inversely associated with foraging behaviour, although, Stafford et al. [44] suggested a direct relationship of D calls with feeding behaviour. Overall, it appears likely that D calls may have a common function (contact) in a variety of behavioural contexts. 

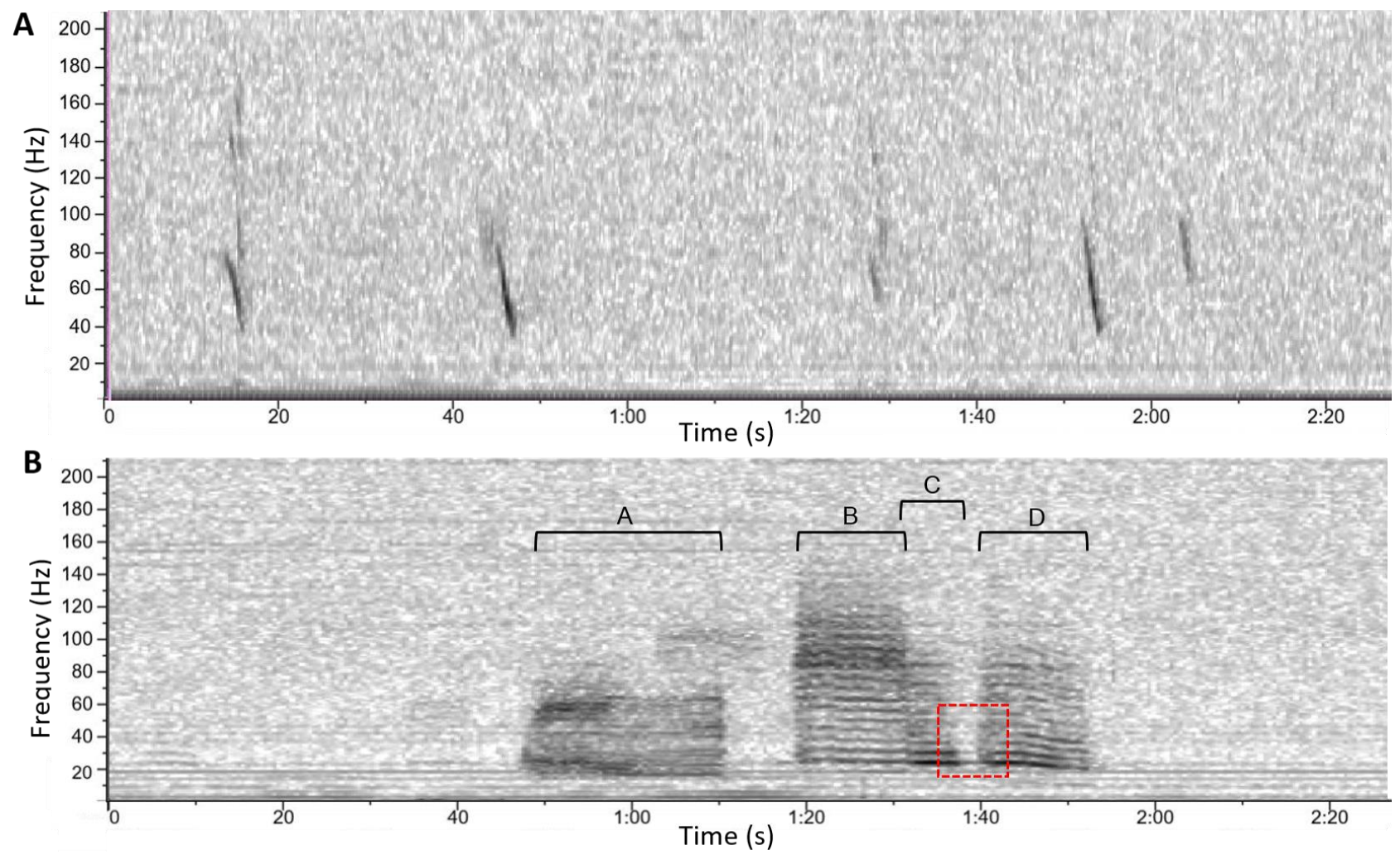

Figure 1. Spectrogram of a series of high-quality D calls (A) and a SEP2 call (B) from this study. SEP call units are marked by A, B, C, D. The red box indicates the portion of the call with higher SNR used to detect fainter calls (see Section 2.1 in the Materials and Methods). Spectrogram parameters: $200 \mathrm{~Hz}$ frequency axis, DFT $=2048$ samples, FFT $=750,10 \%$ overlap and Hann window function. Spectrograms produced with Raven Pro 1.6.

Given the proposed different functions of SEP and D calls, we were interested to learn whether they show similar or different seasonal and geographic patterns of occurrence. Buchan et al. [30,45] analysed seasonal variability in SEP call occurrence in the Chiloense Ecoregion and found higher calling rates during summer and fall months (January-May). Thus, one goal of our study was to examine the seasonal patterns of D calls in this area, and relate them to those of SEP calls. We hypothesized that D call rates would be higher during summer months, when food availability is high and more whales are attracted to the area, while SEP call rates would increase later, as suggested by previous studies $[30,45]$. A second goal was to examine diel patterns of both call types, which is particularly relevant for $\mathrm{D}$ calls as it could provide insights into their function and behavioural context. For example, if $\mathrm{D}$ call production is related to prey availability, higher calling rates would be found during periods of intense feeding, such as during the night when prey patches are closer to the surface [44]. In contrast, if D calls are not related to feeding, higher calling rates would be found when prey patches are more diffuse and foraging efforts less efficient, such as during twilight hours $[9,10,46]$. The recent evidence of D call occurrence in a mating context [43] suggests that the second scenario is more likely. Since SEP calls are considered breeding calls and are thus not related to feeding and prey movements, we predicted that they would not have a clear diel pattern.

\section{Materials and Methods}

Acoustic data from the Chiloense Ecoregion in the south of Chile $\left(\sim 43^{\circ} \mathrm{S}-44^{\circ} \mathrm{S}\right.$, $71^{\circ} \mathrm{W}-73^{\circ} \mathrm{W}$ ) were collected continuously during three five-month deployment periods, from the end of January 2012 to the end of April 2013, using six Marine Autonomous Recording Units (MARUs; Cornell University Laboratory of Ornithology's K. Lisa Yang 
Center for Conservation Bioacoustics, Ithaca, NY, USA) deployed at four different locations: (1) Northwest Chiloe, (2) Guafo North, (3) Tic Toc Bay, and (4) Melimoyu (Figure 2). Deployment details are listed in Table 1 and periods of continuous recordings are visually displayed in Figure 3. MARUs were leased from Cornell University Laboratory of Ornithology's K. Lisa Yang Center for Conservation Bioacoustics (formerly the Bioacoustics Research Program) and were programmed to record at a sampling rate of $2 \mathrm{kHz}$. Acoustic data were recorded to an internal hard drive and were accessible upon instrument recovery; recovered data were then extracted onto an external hard drive. Deployment sites were chosen to provide wide geographic coverage of the Chiloense ecoregion, from offshore areas such as Northwest Chiloe and Guafo North to areas closer to the Chilean continent such as Tic Toc and Melimoyu (Figure 2). Three MARU recovery attempts were unsuccessful; therefore, certain sites lack some temporal coverage [30].

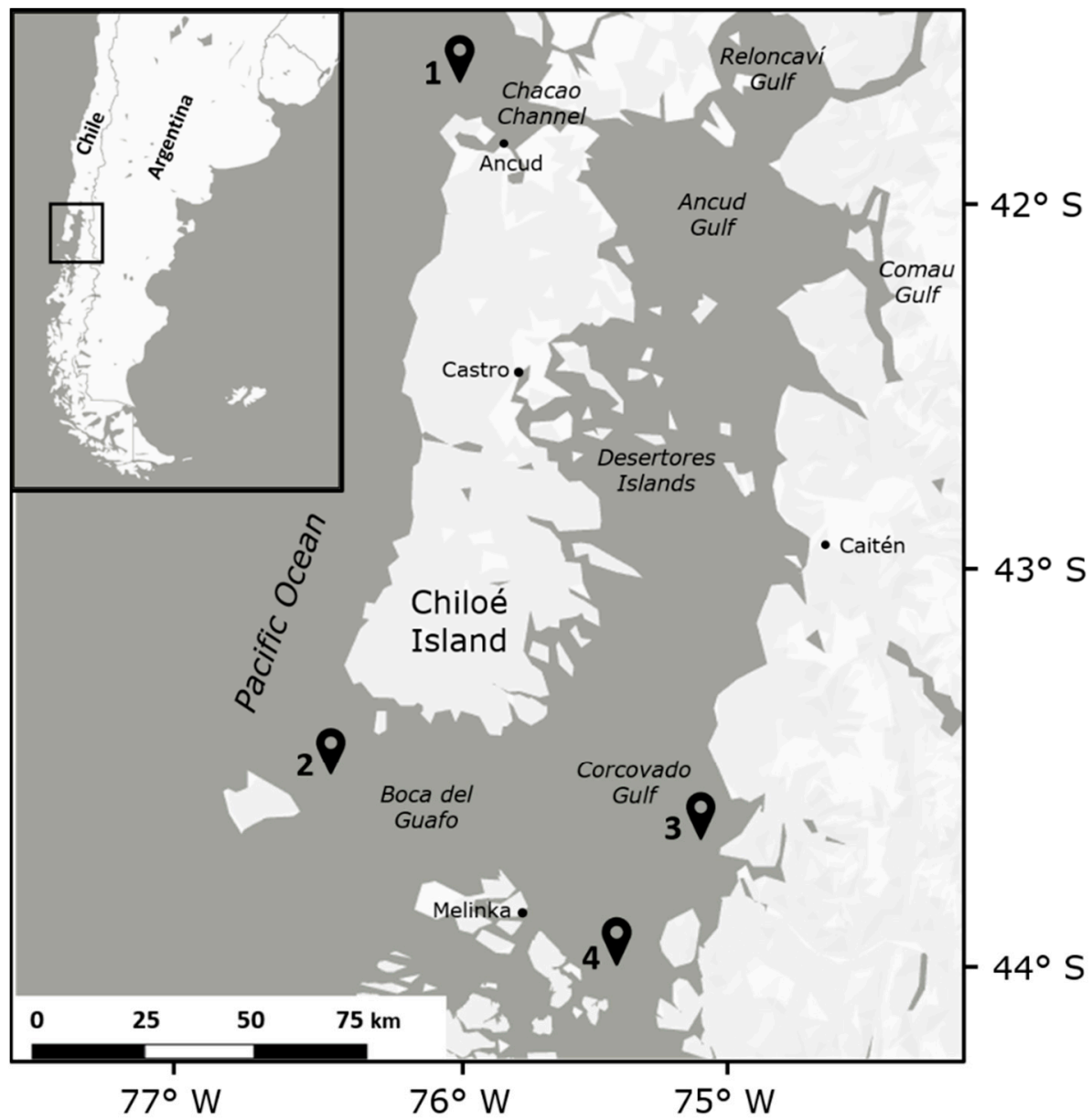

Figure 2. Map of the study area showing the four MARU deployment locations: 1 . Northwest Chiloe, 2. Guafo North, 3. Tic Toc Bay, 4. Melimoyu.

Table 1. MARU deployment details: location, start and end date and total hours of recordings.

\begin{tabular}{ccccc}
\hline Unit & Location & Start Date & End Date & Total Hours \\
\hline MARU 1 & Guafo North & 31 January 2012 & 17 June 2012 & 3370 \\
MARU 2 & Guafo North & 4 December 2012 & 28 April 2013 & 3497 \\
MARU 3 & Melimoyu & 19 June 2012 & 6 December 2012 & 4077 \\
MARU 4 & Melimoyu & 6 December 2012 & 29 April 2013 & 3492 \\
MARU 5 & Northwest Chiloe & 23 January 2012 & 25 June 2012 & 3688 \\
MARU 6 & Tic Toc Bay & 6 December 2012 & 29 April 2013 & 3495 \\
\hline
\end{tabular}




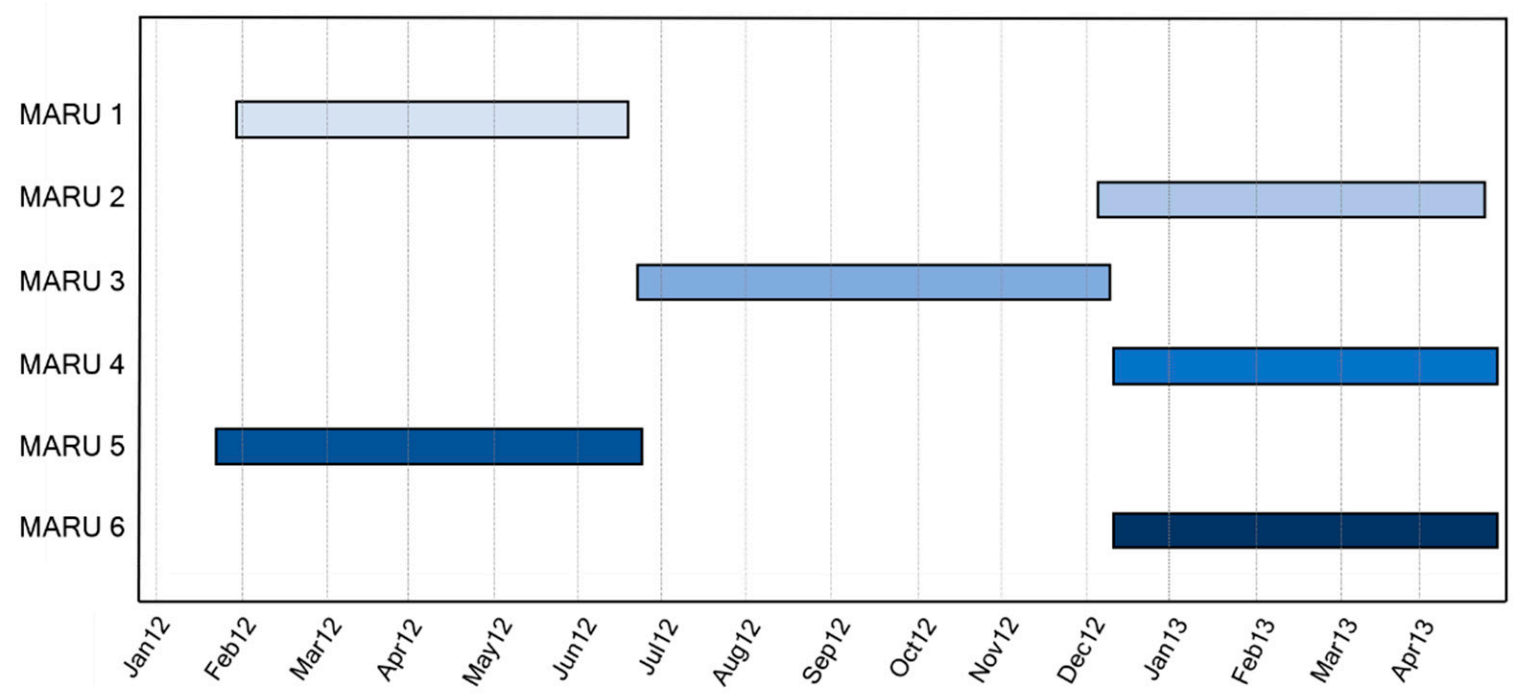

Figure 3. Periods of continuous recordings between January 2012 and April 2013 analysed for each deployment.

\subsection{Blue Whale Sound Detection}

Acoustic data were analysed as spectrograms using Raven Pro 1.6 (The Cornell Lab of Ornithology, Ithaca, NY, USA) [47]. Spectrograms were made using the following display settings: 3 min time axis, $200 \mathrm{~Hz}$ frequency axis, DFT $=2048$ samples, $\mathrm{FFT}=750$, $10 \%$ overlap, and Hann window function. Data were then scanned for the presence of blue whale D and SEP calls using the Raven Pro built-in Band Limited Energy Detector (BLED). The BLED is a window-box detector that has a set of parameters that describe the targeted signal. Detector parameters were developed independently for the two types of calls, due to their different acoustic characteristics, and were tested on a small portion of the data, tuning each parameter until the performance was considered acceptable. All parameters set and tuned are reported in Table 2 and descripted in Raven's user manual [48]. The D call detector was trained on the full duration and frequency spectrum of the target calls, and these parameters were relatively variable across D call exemplars. The SEP call detector targeted both complete calls (Figure 1B, units A, B, C, D) and the end portion of the call (Figure 1B, red box), which typically had a higher signal to noise ratio (SNR), thus enabling the detection of fainter calls. Indeed, since many calls had low SNR, the vast majority of calls were detected through their end portion. During the subsequent visual auditing (see Section 2.2), all detections that picked up only the end portion with higher SNR were manually extended to encompass the whole SEP call.

Table 2. Settings of the BLED detector (see Raven's user manual [48] for descriptions of the parameters).

\begin{tabular}{ccc}
\hline Parameters & $\begin{array}{c}\text { Settings } \\
\text { D Calls }\end{array}$ & SEP Calls \\
\hline Min. frequency (Hz) & 20 & 15 \\
Max. frequency (Hz) & 110 & 60 \\
Min. duration (s) & 0.4 & 5.1 \\
Max. duration (s) & 3.9 & 75 \\
Min. separation (s) & 0.6 & 10.1 \\
Min. occupancy (\%) & 50 & 62.5 \\
SNR threshold & Above 6.0 & Above 11.0 \\
Block size (s) & 4.5 & 200.1 \\
Hop size (s) & 3.9 & 24.9 \\
Percentile & 20.0 & 20.0 \\
\hline
\end{tabular}


Detector performance was not consistent over different months and deployments due to background noise, which often partially or entirely masked blue whale calls, in particular, the shorter and less structured D calls. As it was crucial for the aim of this study to detect as many calls as possible, we assessed detector performance (see the following Section 2.2) via manual audits. D call detections were then visually scanned and assigned to a class of sound quality, using the criteria of Berchok et al. [49]: whether the quality of the signal was sufficient to identify it as a legitimate call, and whether the quality of the signal was sufficient to provide an accurate estimate of its parameters. High and Medium quality calls met both criteria but varied in the amount of noise present, with high-quality calls having the least amount of noise. Low quality calls have low signal-to-noise ratios and were sometimes recognized only through the presence of other calls nearby; therefore, these low-quality calls were not used during analysis of acoustic parameters but were included in diel, seasonal, and geographic pattern analyses. The subset of high-quality detections was used to define acoustic characteristics of blue whale D calls. We focused on minimum, maximum, peak and centre frequency, bandwidth $(\mathrm{Hz})$, and duration (s). For SEP calls, analysis of acoustic characteristics was not performed, as they were already described for this region by Buchan et al. [27] and Saddler et al. [50].

For each of the six deployments, we audited every other day's worth of data, for a total of 447 days $(10,728 \mathrm{~h}$, or 15 months) of recordings. We chose this approach as a time saving measure, rather than analysing the entire data set, and we believe that this sub-sampling method captured any temporal or geographic patterns in the data. For each deployment, the first day of the analyses corresponded to the first full day recorded (from 0 a.m. to 24 p.m.) and ended with the last full day recorded.

\subsection{Detector Performance}

In order to assess detector performance, we first picked three days from each deployment, one at the beginning, one in the middle, and one towards the end. To determine the number of false positives, we visually scanned all of the detector's selections for both $\mathrm{D}$ and SEP calls, and we scanned the entire audio recordings of those days to determine the number of missed detections. D calls are highly variable in frequency range, making it difficult for the energy band detector to be consistent among different recordings. In addition, their short duration make D calls easily masked by other sounds. Conversely, SEP calls have a more stereotyped acoustic structure and longer duration, enabling the detector to perform more consistently. Missed D call rate (number of missed detections/total number of detections) for the chosen detector threshold varied from 10 to $27 \%$ in different recordings. False detections of $\mathrm{D}$ calls were also highly variable among deployments, and were mainly caused by anthropogenic and biological noise events (i.e., boat noise and fish sounds) as well as undefined sounds. False detection rate (number of false detections/total number of detections) for $\mathrm{D}$ calls ranged from 40 up to $97 \%$ in the noisiest days and deployments over the recording period. On the other hand, the missed SEP call rate was consistent at around $16 \%$ in all recordings, while false detections were around $26 \%$ of total detections, although highly variable due to background noise. Due to this extremely high variability in detector performance, we visually audited the automatic detections for both type of calls, manually removing false detections and adding missed ones, for all 10,728 h of recordings. Therefore, while we had to manually check all of the audio files, the employment of the automatic detector helped to speed up the annotation process as a significant number of true detections were already selected and we only needed to validate them.

\subsection{Analysis of Acoustic Parameters}

While SEP calls have a clearly distinctive acoustic structure [27,35], downsweep calls can be more difficult to identify with certainty, especially in the presence of vocalizations from other whale species. Several mysticete species can produce calls similar to blue whale $\mathrm{D}$ calls in terms of frequency range and down-sweeping pattern, including fin whales (Balaenoptera physalus; 30-100 Hz) [51], sei whales (Balaenoptera borealis; 35-100 Hz, 
occurring in singles, doublets, or triplets) [52], and minke whales (Balaenoptera acutorostrata; $50-130 \mathrm{~Hz}$ ) [53]. In an effort to include in our analyses only downsweep (D) calls from blue whales, we performed a preliminary analysis of acoustic parameters of all detected calls (low, medium, and high-quality) and excluded detections that had a minimum frequency lower than $30 \mathrm{~Hz}$, maximum frequency higher than $121 \mathrm{~Hz}$, and a duration shorter than $0.90 \mathrm{~s}$ or longer than $3.71 \mathrm{~s}$. These cut-offs were chosen to exclude detections that exceeded the values for $75 \%$ of the calls. While exclusion of these detections may have eliminated some blue whale D calls with more extreme acoustic characteristics, it likely also reduced the number of calls from other baleen whale species in our analysis.

\subsection{Diel, Seasonal and Geographic Patterns}

Day of the year and location of each detection were used to estimate seasonal and geographic variability of blue whale D and SEP call rates. We report the average number of each type of call from all MARUs, normalized by the number of MARUs that were recording each day [54]. To explore seasonality, we show the average number of D and SEP call detections for each deployment site over the whole recording period (January 2012-April 2013). In addition, we calculated the ratio of each type of call for each location to see whether a certain type of call is more likely to occur in offshore rather than inshore sites or vice versa.

To study diel calling patterns of Chilean blue whales, call detections were sorted into four light regimes based on the altitude of the sun: dawn, light, dusk, and night. Dawn and dusk hours were defined as when the sun was between $12^{\circ}$ to $0^{\circ}$ below the horizon (respectively morning nautical twilight to sunrise and sunset to evening nautical twilight); day hours are between sunrise and sunset, when the sun is more than $0^{\circ}$ over the horizon, and night hours are between morning and evening nautical twilight, when the altitude of the sun is less than $-12^{\circ}$. As data were recorded using GMT time zone, detection times were adjusted for Chilean time (GMT-3/-4) before temporal patterns were analysed.

Daily hours of sunset, sunrise and nautical twilight were obtained using the 'suncalc' package [55] in R software version 3.6.0 (R Foundation for Statistical Computing, Vienna, Austria) [56] for the coordinates of the study location, corrected to local time. Only days with at least one detection were used for diel pattern analysis. Daily number of detections in each light regime was calculated, and divided by the duration of the corresponding light period for a given day, to account for differences in duration between the four light regimes. The resulting normalized detection rates (in detections $/ h$ ) for each light regime and each day were then adjusted by subtracting the mean number of detections per hour of the corresponding day (Mean adjusted no. of detections/h) [10]. Distributions of call types in different sites, months, or light regimes were not normally distributed, so we looked for differences using Kruskal-Wallis tests [57]. In cases where there were significant differences between distributions, post-hoc Wilcoxon pairwise comparison tests with Bonferroni corrections were used. Statistical analyses were performed using R.

\section{Results}

In total, 37,141 D and 63,255 SEP calls were automatically detected and manually verified (see Materials and Methods). We detected 596 high quality, 13,499 medium quality, and 23,046 low quality D calls.

\subsection{Call Acoustic Characteristics}

The acoustic parameters of a subset of 596 high quality D calls are reported in Table 3. 
Table 3. Mean, standard deviation (SD), minimum, maximum, and median values for various frequency parameters (in $\mathrm{Hz}$ ) and duration (in seconds) of high-quality $\mathrm{D}$ calls $(n=596)$. * Value set a priori, in order to avoid inclusion of other species' calls (see Section 2.3 in the Materials and Methods).

\begin{tabular}{cccccccc}
\hline & Frequency (Hz) & & & \\
\hline & Minimum & Maximum & Peak & Centre & \multicolumn{2}{c}{ Duration (s) } & Bandwidth (Hz) \\
\hline Mean & 34.9 & 102.0 & 58.3 & 59.2 & 1.69 & 37.7 \\
\hline SD & 5.94 & 10.8 & 13.4 & 10.1 & 35.2 & 0.69 & 10.4 \\
\hline Min & $30.0 *$ & 72.3 & 31.2 & 113.0 & 97.7 & $3.71^{*}$ & 74.2 \\
\hline Max & 61.1 & $121.0 *$ & 54.7 & 58.6 & 1.54 & 35.2 \\
\hline Median & 32.9 & 110.0 & & & & \\
\hline
\end{tabular}

\subsection{Seasonal Patterns}

Due to the lack of consecutive temporal coverage in the recordings, it was not possible to assess seasonal occurrence of Chilean blue whale calls for all sites. We had recordings from 10 consecutive months (19 June 2012-28 April 2013) for just one site, Melimoyu. For this site, we observed a very low number of both call types during winter months (June-August) and a gradual increase in warmer months, with a delayed peak of SEP calls over D calls (Figure 4). D calls (Figure 4A) showed a somewhat gradual increase during spring (September-November) and summer months (December-February), peaking in January, and decreasing towards fall months (March and April). Other than a peak in June, which likely carried out from the previous spring, SEP calls (Figure 4B) instead were absent for most winter and spring months (July-November) and started to gradually increase in summer and fall months, peaking between March and April.

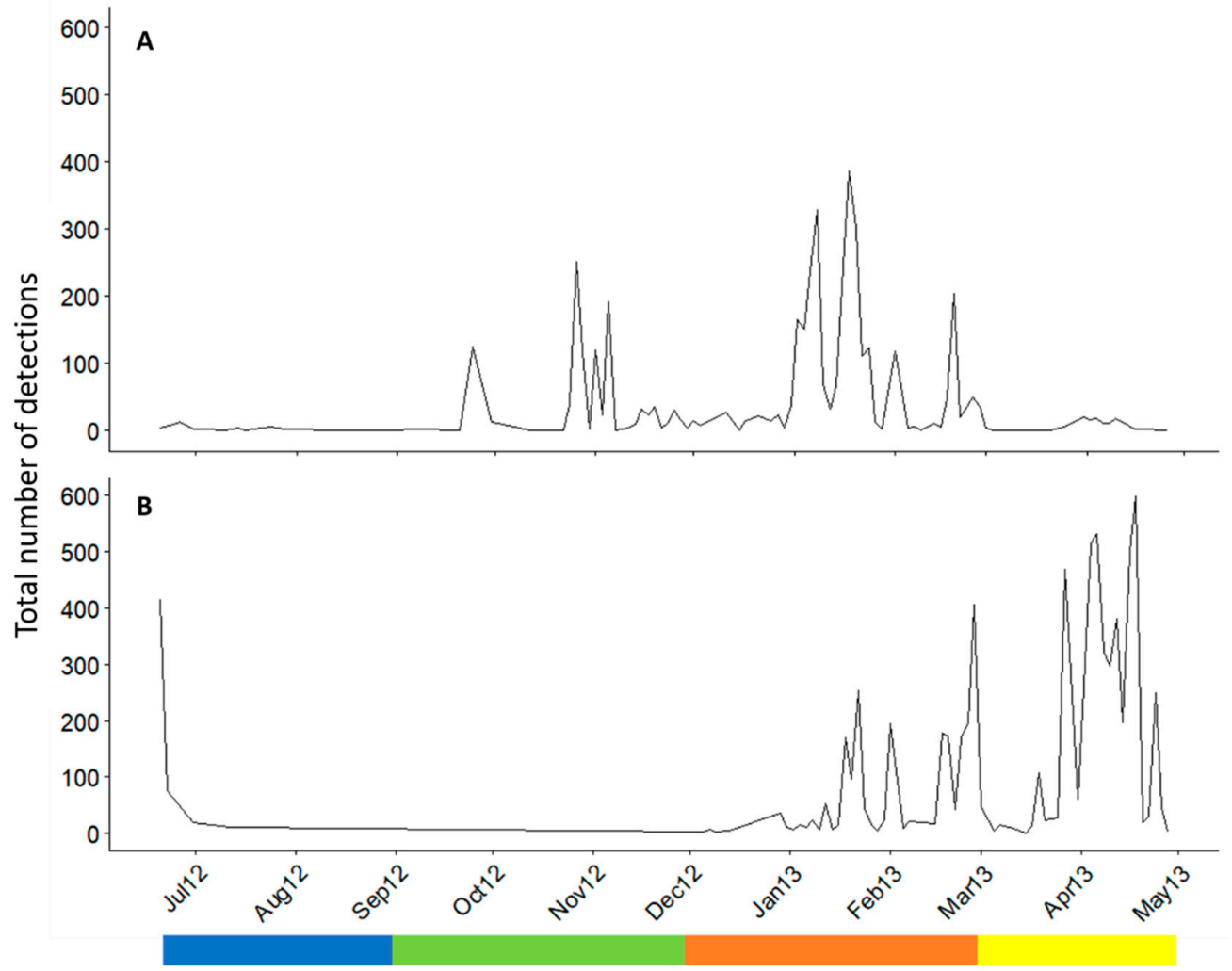

Figure 4. Total number of D (A) and SEP (B) call detections for 10 consecutive months of recording in Melimoyu: 19 June 2012-28 April 2013. Color bar represents seasons (blue: winter; green: spring; orange: summer; yellow: fall). 


\subsection{Geographic Variation}

The four deployment sites were spread over a relatively wide area and thus covered both offshore and inshore locations (Figure 5). In particular, we considered Guafo North and Northwest Chiloe as offshore sites and Melimoyu and Tic Toc Bay as inshore sites. There was significant variability in the call production rates among the four sites (Figure 5), but offshore sites had consistently higher call rates than inshore sites. For D calls, the normalized number of detections (total number of detections/months recorded) were: 2233 in Guafo North, 3721 in Northwest Chiloe, 380 in Melimoyu, and 276 in Tic Toc Bay. For SEP calls, the normalized number of detections were: 3626 in Guafo North, 2648 in Northwest Chiloe, 688 in Melimoyu, and 751 in Tic Toc Bay.
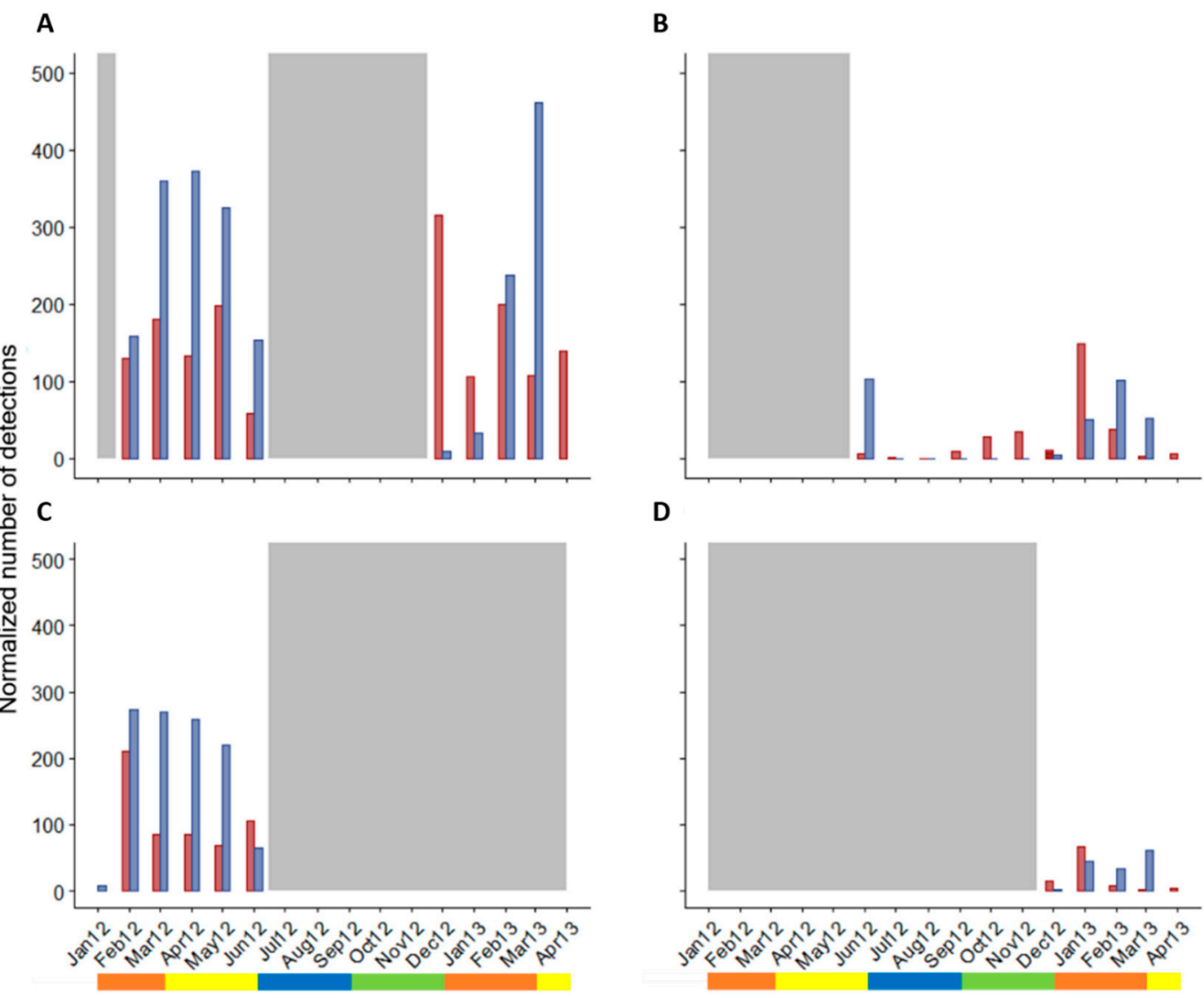

Figure 5. Normalized number of monthly D (red) and SEP (blue) call detections for each site: Guafo North (A), Melimoyu (B), Northwest Chiloe (C) and Tic Toc Bay (D). Periods shaded in grey indicate times when no data were collected. Colour bars represent seasons (orange: summer; yellow: fall; blue: winter; green: spring).

SEP calls were always the prevalent type of call, representing between $61.9-73.1 \%$ of total calls at each site. D calls ranged between 26.9 and 38.1\% of total calls at each site (Table 4).

Table 4. Percentages of call types at each recording site.

\begin{tabular}{ccc}
\hline Site & D Calls & SEP Calls \\
\hline Guafo North & 38.1 & 61.9 \\
Northwest Chiloe & 35.4 & 64.6 \\
Melimoyu & 35.6 & 64.4 \\
Tic Toc Bay & 26.9 & 73.1 \\
\hline
\end{tabular}




\subsection{Diel Patterns}

Hourly differences were observed in blue whale D call rates but not SEP call rates for all recording sites (Figure 6). We observed more D calls during late afternoon, evening, and night than during early morning and day hours (Figure 6), and these differences were statistically significant (Figure 7; Kruskal-Wallis, $\chi^{2}=46.51$, df $=3, p$-value $<0.001$ ). Dawn and dusk, dawn and night, day and dusk, and day and night periods were all significantly different from one another $(p<0.05)$, while comparisons between dawn and day and between dusk and night were non-significant $(p=1 ;=0.1763$-Figure 7A). In contrast, there were no significant differences in SEP calling rate during different light periods (Kruskal-Wallis $\chi^{2}=3.3264, \mathrm{df}=3, p$-value $=0.344$-Figure 7B).
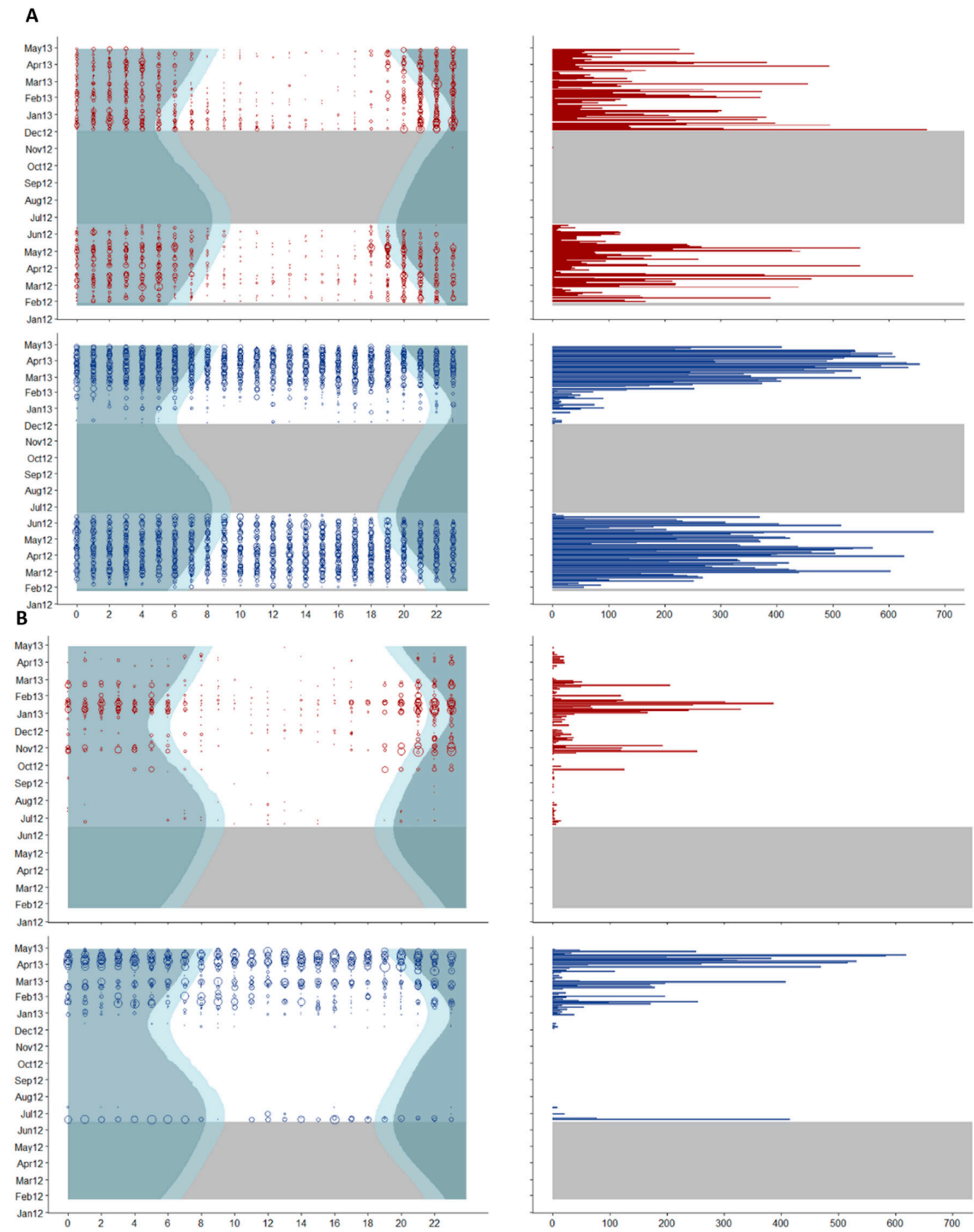

Figure 6. Cont. 


\section{C}
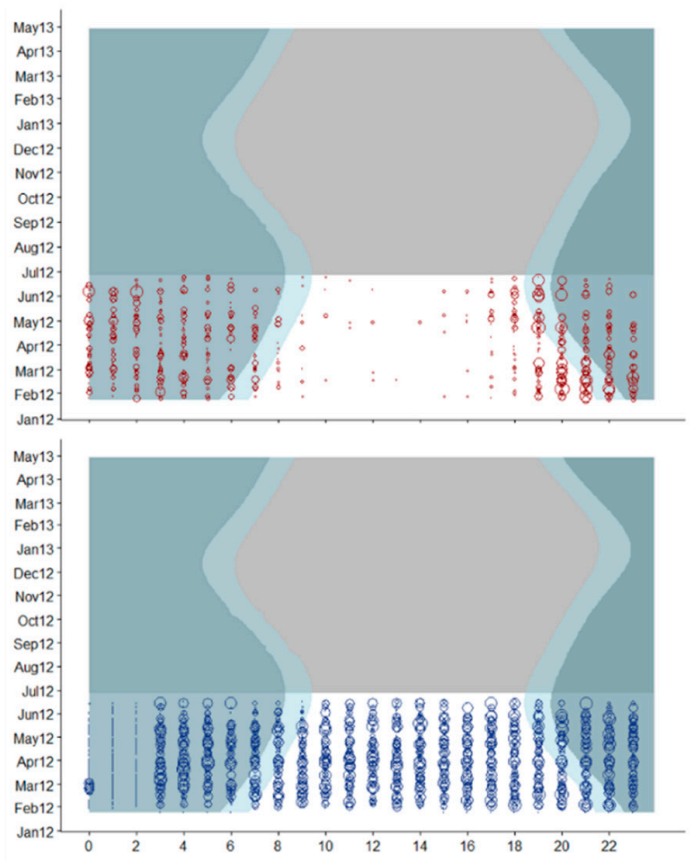

\section{D}

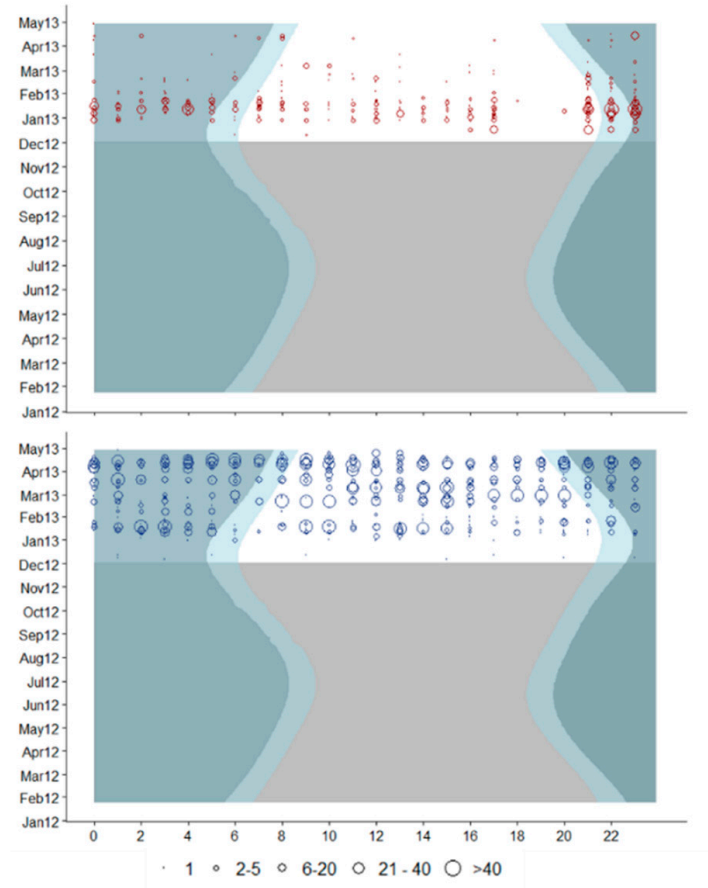

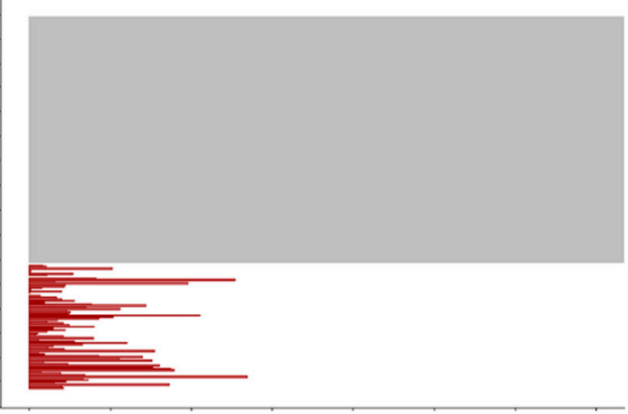
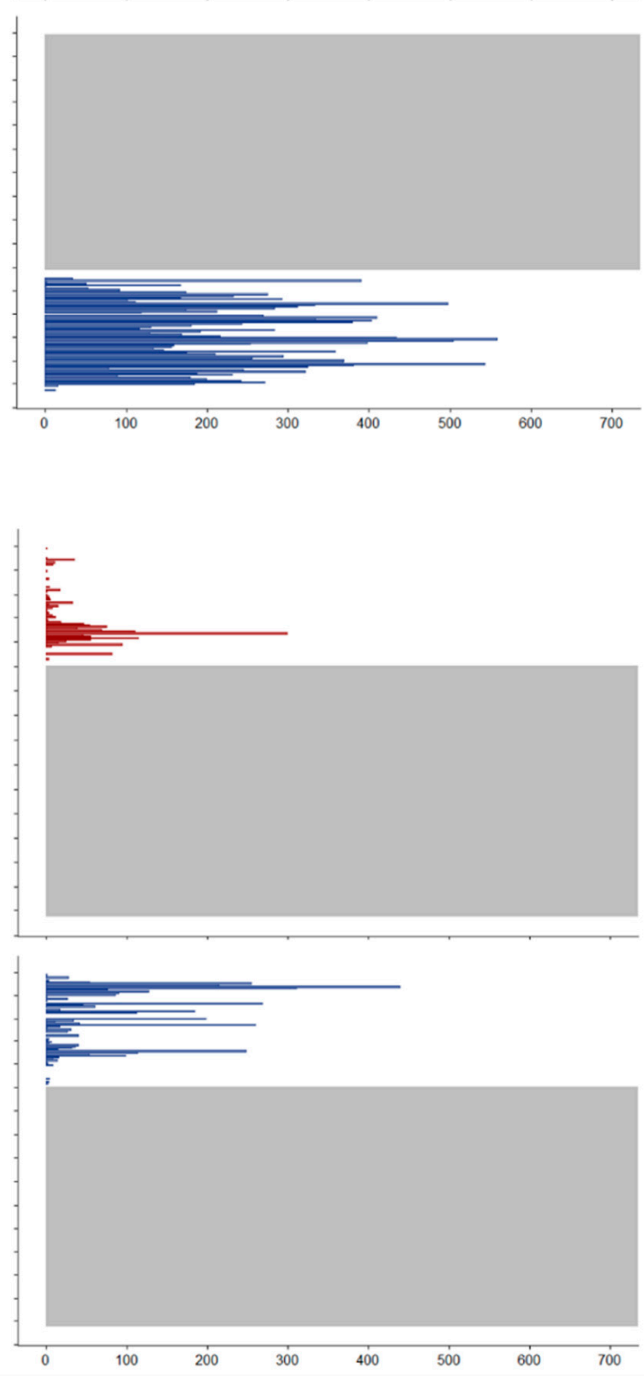

Figure 6. Diel distribution of blue whale D (red) and SEP (blue) call detections for each recording site: Guafo North (A), Melimoyu (B), Northwest Chiloe (C) and Tic Toc Bay (D). Left x-axis shows hour in Chilean Standard Time (CST); the right x-axis shows the daily total number of calls; $y$-axis shows the dates. Circles indicate the numbers of calls per hour, and the circle size is explained in the legend below the figure. Dark blue shading shows night periods, light blue shading shows twilight periods. Grey shading indicates periods of no recordings. 

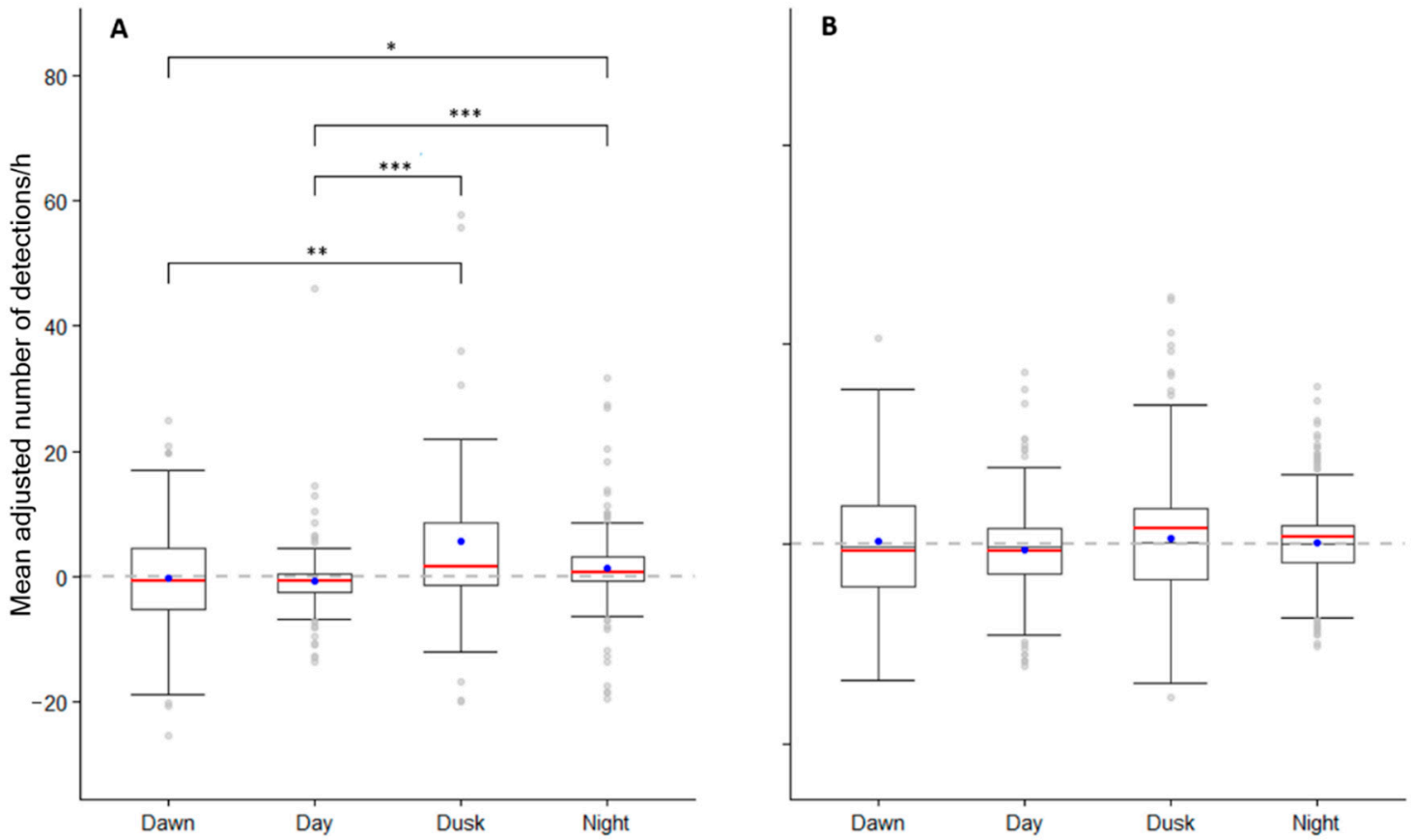

Figure 7. Boxplot of mean-adjusted number of D (A) and SEP (B) call detections per hour during four light regimes. Lower and upper bounds of whiskers represent lower and upper quartiles respectively. Red lines are median values, blue dots are mean values, and grey dots represent outliers. Asterisks denote statistically significant differences: ${ }^{*}=p<0.05 ;{ }^{* *}=p<0.01 ;{ }^{* *}=p<0.001$. Note that means can differ from medians due to outliers.

\section{Discussion}

Passive acoustic monitoring is one of the most effective and non-invasive tools to collect data about cetacean occurrence, but data are often not accompanied by visual observations. Thus, it is impossible to know if more calls are the result of individuals calling more or a greater number of individuals, and likewise if the absence of calls is due to the absence of whales or vocal behaviour [58]. Following previous PAM studies [54,59-62], we assumed that more calls indicate more whales. In addition, we assumed that diel variations in calling rates represent more vocal behaviour from individual whales [63], rather than movement in and out of these areas. These assumptions must be viewed with caution until more tag or observational data are collected for this population.

\subsection{Call Acoustic Characteristics}

Our measurements of $\mathrm{D}$ call acoustic parameters were in close agreement to those reported by Saddler et al. [50] for a small sample of D calls from tagged whales in the Chiloense ecoregion. We can thus say that Chilean blue whale D calls typically range from 35 to $102 \mathrm{~Hz}$, and last approximately $1.6 \mathrm{~s}$. Our results also suggest that Chilean blue whale D calls have a slightly shorter duration than those of other populations: durations have been reported at $1.8 \mathrm{~s}$ for the North Pacific [28], $2 \mathrm{~s}$ for the North Atlantic [49], 2.1-2.5 s for the Southern Ocean [64,65], and 2-4 s for pygmy blue whales of the Indian Ocean [37]. Moreover, Chilean D calls show a wider frequency range compared to most other populations (North Pacific 39.3-75.7 Hz; North Atlantic: 37.8-88.3 Hz; Southern Ocean: $38-80 \mathrm{~Hz})[28,49,64,65]$, except for Indian Ocean pygmy blue whales (20-100 Hz) [37].

\subsection{Seasonal Occurrence of Chilean Blue Whales in the Chiloense Ecoregion}

Our data set included only one site (Melimoyu) with consecutive temporal coverage across four seasons. At this site, very few calls occurred in winter, while call rates gradually increased toward the summer months. The D call rate started to increase in spring and 
peaked in January, during summer, while SEP calls appeared towards the end of December and peaked between March and April, during fall. Thus, the increase and peak of SEP calls is delayed by about two months with respect to the trend for D calls. Although we cannot draw conclusions on the seasonality of blue whale presence in the area (due to lack of consecutive temporal coverage for all sites, as mentioned above) our findings are in agreement with those of a recent study by Buchan et al. [45] (and of Buchan et al. [30] on SEP calls only). Buchan et al. [45] described seasonal and geographic variation in D and SEP calls in relation to zooplankton backscatter and oceanographic variables. As previously reported, they found that SEP calls were mostly present during the austral summer and fall months (January-May), peaking in April, while D calls were present between December and May. The authors found that D calls did not show a clear seasonal pattern, but peaked twice during this six-month period, and were highly correlated to sub monthly zooplankton aggregations [45].

Blue whales congregate in mid/high-latitude feeding grounds where high seasonal density of prey, such as euphausiids, are predictable as result of high primary productivity [66]. The Chiloense ecoregion has proven to be an area with high and strongly seasonal primary productivity, with a peak in summer [67]. The main mesozooplanktonic species in the area is the euphausiid Euphausia vallentini [68], which significantly increases in abundance between spring and summer (October-December) and reaches a peak in late summer $[45,69,70]$. Thus, our observed increase in $\mathrm{D}$ call detections during austral summer follows the pattern of euphausiid abundance, which likely reflects a greater number of whales in the area when there is more prey. Moderate sub monthly variations in $\mathrm{D}$ call rates (i.e., during fall months; Figure $4 \mathrm{~A}$ ) might be related to short term variations in prey abundance and patchiness [45,71] or to mating aggregations [43].

The SEP call rate increased later than D calls (January-April; this study, Buchan et al.) [30,45]. Due to their patterned sequence, SEP calls are considered a distinct song type from the southeast Pacific blue whale population [27]. While breeding is thought to occur primarily in winter and spring, occurrence of song in the summer and fall on feeding grounds might serve to promote pair bonding for the upcoming breeding season or to advertise to oestrous females, as was proposed for humpback whale (Megaptera novaeangliae) singing behaviour on feeding grounds [58,72]. Moreover, the delayed peak of SEP calls over D calls might suggest that some males have consumed enough prey to enable them to spend more time singing. In addition, recent evidence of the use of D calls in a reproductive context [43] supports the idea that blue whales do not exclusively forage on feeding grounds, but also perform a wide variety of social behaviours.

D calls were detected during winter and spring months (June-November) while SEP calls were absent from the end of June until December. Therefore, it appears that some individuals, possibly immature females and juveniles, remain in the habitat longer, similarly to what has been reported for humpback whales [73] and Antarctic blue whales [74]. Findings from visual, genetic [75,76], and acoustic studies [27] suggest that these whales migrate thousands of kilometres to reach the winter breeding ground in the Eastern Tropical Pacific (Costa Rica Dome, Galapagos waters). Undoubtedly, this migration can be extremely demanding; thus, some animals might skip the migration to diminish energy expenditure and extend exploitation of food sources on feeding grounds [73]. This is especially likely for juveniles that have not yet reached sexual maturity, and are thus not ready to breed on the breeding grounds. Indeed, recent studies on mesozooplankton abundance show that the main euphausiid species in the Corcovado gulf, E. vallentini, is present year-round [45,70]. The fact that from June to November calls produced only by reproductive males (SEP calls) were absent, while calls produced by both sexes (D calls) were present, although very few, supports the idea that some animals may stay in the area to feed. However, we analysed seasonality at only one site, and there are likely other factors influencing call production beyond season. As Buchan et al. [30] suggested, long-term oceanographic and passive acoustic datasets are necessary to gain a more comprehensive understanding of 
how the seasonal presence of blue whales may be linked to oceanographic processes in the Chiloense ecoregion feeding ground.

\subsection{Geographic Variation}

Higher detection rates of both call types occurred at offshore (Guafo North and Northwest Chiloe) vs. inshore (Melimoyu and Tic Toc Bay) sites. One factor that might affect this difference is that offshore sites might receive signals from a greater area than inshore sites, and thus may record more distant whales. Alternatively, higher call rates might reflect that there are more whales foraging offshore [26]: food rich areas allow animals to feed more efficiently and thus spend more time producing calls. Baleen whales tend to be more abundant where prey availability is greater; offshore sites may have higher zooplankton biomass because of oceanographic features that cause zooplankton to aggregate further from the coast [69]. However, as our study area was relatively limited in spatial scale, it is more likely that variability between sites is due to finer-scale patchiness in euphausiid densities during our study period. Indeed, the preferred blue whale prey in the area, E. vallentini, is characterized by patchy distributions $[33,67,69,77]$. However, future studies that combine blue whale acoustic behaviour with concurrent prey measurements are necessary to assess this hypothesis.

At all sites, SEP calls were more abundant than D calls, accounting for $61-73 \%$ of all detected calls. This might be due to $\mathrm{D}$ calls being related to certain contexts, whereas SEP calls may be produced by whales regardless of activity. This idea is also supported by the fact that D calls show diel patterns, whereas SEP calls do not (see Section 4.4 below). Our findings are in agreement with previous studies of other blue whale populations $[26,28,37,58]$ that found rates of these two call types to be significantly different and song to be the prevalent call type. Indeed, while songs are produced in series, and a single male can sing for several hours consecutively [29], D calls usually occur with irregular patterns of shorter duration. However, another likely contributing factor is simply that SEP calls are louder, and thus travel greater distances than D calls, as reported in previous studies [45,49]. This would make sense based on their function as a reproductive advertisement display [78]. Thus, SEP call counts may represent whales from a wider range than D call counts do. Further research is clearly needed to determine the contexts of both call types in different geographic areas.

\subsection{Diel Patterns}

For all sites, there was no diel pattern in SEP calls, indicating that males produce these calls regardless of the time of the day. In particular, we found SEP diel distribution to be homogenous between seasons, thus not showing any acoustic signature of behavioural transition as found by Oestreich et al. [11].

In contrast, $\mathrm{D}$ call detections were more numerous during dark hours than during dawn and daytime hours. This may suggest that $\mathrm{D}$ calls are associated with zooplanktonic vertical migration. Most euphausiid species, including Chilean blue whales' main prey, E. vallentinii, descend to deeper waters during the day and rise toward the surface at night [79-81]. Chilean blue whales may forage more during the day when preys are aggregated at depth, and feed less during dusk and night hours when prey patches are more diffuse at the surface. This idea is supported by a recent study by Lewis and Širović [58], in which the use of animal borne tags showed that $\mathrm{D}$ calls were mostly produced when animals were near the surface and rapidly decreased when they were more than $20 \mathrm{~m}$ deep. Thus, as outlined earlier, it appears unlikely that $\mathrm{D}$ calls are directly related to feeding. Payne and Webb [82] hypothesized that baleen whale social structure might consist of a so-called 'range herd' in which individuals maintain acoustic contact over large areas. This ability would free them from the constraint of having to be in a certain place at a certain time, and individuals could migrate to different areas, for example to take advantage of different feeding opportunities. The authors also proposed that wellfed whales vocalize and that hungry whales head towards the greatest source of sounds. 
Individuals might thus be able to optimize the search for both food and conspecifics in a patchy environment that may vary seasonally and inter-annually. Therefore, while D calls function(s) remain unknown, it appears likely that they broadly serve in maintaining contact with other individuals $[23,26,43]$. The tonal, downswept nature of D calls may provide cues for binaural localization, and might be more detectable above background noise than broadband calls such as SEP calls [83]. Use of tonal up-swept or down-swept calls for locating conspecifics has been shown for right and fin whales $[84,85]$; production of D calls among groups of widely separated blue whales might suggest a similar role [26]. However, more acoustic data coupled with visual observations are necessary to confirm our hypothesis and to understand all the possible behavioural contexts in which these calls may be used.

\section{Conclusions}

Knowledge of behavioural contexts of call production, as well as geographic and temporal variation, are necessary to understand how acoustic communication functions for a given species. Although other types of data, such as photo-identification, biopsies, or tagging, would be necessary to gain a more fine-scale understanding of communication, passive acoustic data can play an important role in the conservation of endangered species. PAM can provide information about geographic and seasonal distributions in regions that are difficult to monitor visually. Our results provide insights into the behaviour and ecology of Chilean blue whales at different temporal scales, which could inform future passive acoustic monitoring efforts by suggesting when they would be most effective. In addition, these results provide a better understanding of when, where, and possibly how these different call types are used by Chilean blue whales.

Author Contributions: L.R. and L.S. conceived the study and wrote the paper; L.R. performed the formal analysis and developed the methodology and visualization; L.R. and S.M.W. tuned the parameters of the automatic detector and carried out the investigation on the original recordings; R.L. provided the resources and funding for the field work expeditions; L.S. supervised and administrated the project and cured the data. All authors have read and agreed to the published version of the manuscript.

Funding: Financial support for expeditions, deployments, and retrievals of MARUs, and for some of the data analysis, was provided by Fundacion MERI, Av. Pdte. Kennedy 5682, Vitacure, Región Metropolitana, Chile. The data analysis for this study was carried out without external funding.

Institutional Review Board Statement: Not applicable.

Informed Consent Statement: Not applicable.

Data Availability Statement: The data presented in this study are openly available in WHOAS repository [https:/ / hdl.handle.net/1912/27919] (accessed on 13 January 2022), doi:10.26025/1912/27919.

Acknowledgments: Thanks to Rodrigo Hucke-Gaete, Susannah Buchan, and the Centro Ballena Azul for their participation in the expeditions to deploy MARUs, and to Fundacion MERI for providing financial support for the deployments, as well as for some data analysis. We also thank Thomas Montt, Sociedad Pesquera y de Turismo Marítimo Los Elefantes Ltd.a., Pedro Montt 215, Dalcahue-Chiloe, Chile, for his support (and that of his crew) in cruise logistics, and for deploying and retrieving instruments. Finally, thanks to Alessandro Bocconcelli for support in project logistics, to Songhai $\mathrm{Li}$ for his support in the publication of this paper, and to Thomas Uboldi for his continuous support to our research.

Conflicts of Interest: The authors declare no conflict of interest.

\section{References}

1. Goldbogen, J.A.; Friedlaender, A.S.; Calambokidis, J.; Mckenna, M.F.; Simon, M.; Nowacek, D.P. Integrative approaches to the study of baleen whale diving behavior, feeding performance, and foraging ecology. Bioscience 2013, 63, 90-100. [CrossRef]

2. Marques, T.A.; Munger, L.; Thomas, L.; Wiggins, S.; Hildebrand, J.A. Estimating North Pacific right whale Eubalaena japonica density using passive acoustic cue counting. Endanger. Species Res. 2011, 13, 163-172. [CrossRef] 
3. Zimmer, W.M. Passive Acoustic Monitoring of Cetaceans; Cambridge University Press: Cambridge, UK, 2011.

4. Au, W.W.; Mobley, J.; Burgess, W.C.; Lammers, M.O.; Nachtigall, P.E. Seasonal and diurnal trends of chorusing humpback whales wintering in waters off western Maui. Mar. Mammal Sci. 2000, 16, 530-544. [CrossRef]

5. Carlström, J. Diel variation in echolocation behavior of wild harbor porpoises. Mar. Mammal Sci. 2005, 21, 1-12. [CrossRef]

6. Palmer, J. An Introduction to Biological Rhythms; Elsevier: Amsterdam, The Netherlands, 2012.

7. Goold, J.C. A diel pattern in vocal activity of short-beaked common dolphins, Delphinus delphis. Mar. Mammal Sci. 2010, 16, 240-244. [CrossRef]

8. Baumgartner, M.F.; Fratantoni, D.M. Diel periodicity in both sei whale vocalization rates and the vertical migration of their copepod prey observed from ocean gliders. Limnol. Oceanogr. 2008, 53, 2197-2209. [CrossRef]

9. Jacobs, E.; Madsen, P.; Landea, R.; Bocconcelli, A.; Sayigh, L. Temporal trends and noise effects on of upsweep calls of Eastern South Pacific southern right whales. Manuscript submitted for publication.

10. Wiggins, S.M.; Oleson, E.M.; McDonald, M.A.; Hildebrand, J.A. Blue whale (Balaenoptera musculus) diel call patterns offshore of Southern California. Aquat. Mamm. 2005, 31, 161. [CrossRef]

11. Oestreich, W.K.; Fahlbusch, J.A.; Cade, D.E.; Calambokidis, J.; Margolina, T.; Joseph, J.; Friedlander, A.R.; McKenna, M.F.; Stimpert, A.K.; Southall, B.L.; et al. Animal-borne metrics enable acoustic detection of blue whale migration. Curr. Biol. 2020, 30, 4773-4779. [CrossRef]

12. Laws, R.M. Seals and whales of the Southern Ocean. R. Soc. Lond. B 1977, 279, 81-96. [CrossRef]

13. IUCN. Cetacean update of the 2008 IUCN Red List of Threatened Species. In IUCN Redlist of Endangered Species; IUCN: Gland, Switzerland, 2008.

14. Halpern, B.S.; Frazier, M.; Afflerbach, J.; Lowndes, J.S.; Micheli, F.; O’Hara, C.; Scarborough, C.; Selkoe, K.A. Recent pace of change in human impact on the world's ocean. Sci. Rep. 2019, 9, 11609. [CrossRef]

15. Hucke-Gaete, R.; Osman, L.P.; Moreno, C.A.; Findlay, K.P.; Ljungblad, D.K. Discovery of a blue whale feeding and nursing ground in southern Chile. Proc. R. Soc. Lond. B 2004, 271, S170-S173. [CrossRef] [PubMed]

16. Galletti Vernazzani, B.; Jackson, J.A.; Cabrera, E.; Carlson, C.A.; Brownell, R.L. Estimates of abundance and trend of Chilean blue whales off isla de Chiloé, Chile. PLoS ONE 2017, 12, e0168646. [CrossRef] [PubMed]

17. Aguayo, L.A. Baleen whales off continental Chile. In The Whale Problem: A Status Report; Harvard University Press: Cambridge, MA, USA, 1974; Chapter 8, pp. 209-217. [CrossRef]

18. Rice, D.W. Marine Mammals of the World: Systematic and Distribution; Allen Press: Lawrence, KS, USA, 1998.

19. Khalaf-Prinz Sakerfalke von Jaffa, N. The Chilean Blue Whale (Balaenoptera musculus chilensis Khalaf, 2020): A New Subspecies from Chile. Gazelle Palest. Biol. Bull. 2020, 38, 40-63.

20. Branch, T.A.; Stafford, K.M.; Palacios, D.M.; Allison, C.; Bannister, J.L.; Burton, C.L.K.; Cabrera, E.; Carlson, C.A.; Galletti Vernazzani, B.; Gill, P.C. Past and present distribution, densities and movements of blue whales Balaenoptera musculus in the Southern Hemisphere and northern Indian Ocean. Mammal Rev. 2007, 37, 116-175. [CrossRef]

21. LeDuc, R.G.; Dizon, A.E.; Goto, M.; Pastene, L.A.; Kato, H.; Nishiwaki, S.; LeDuc, C.A.; Brownell, R.L. Patterns of genetic variation in Southern Hemisphere blue whales and the use of assignment test to detect mixing on the feeding grounds. J. Cetacean Res. Manag. 2007, 9, 73.

22. Pastene, L.A.; Acevedo, J.; Branch, T.A. Morphometric analysis of Chilean blue whales and implications for their taxonomy. Mar. Mammal Sci. 2020, 36, 116-135. [CrossRef]

23. McDonald, M.A.; Calambokidis, J.; Teranishi, A.M.; Hildebrand, J.A. The acoustic calls of blue whales off California with gender data. J. Acoust. Soc. Am. 2001, 109, 1728-1735. [CrossRef]

24. Bouffaut, L.; Landrø, M.; Potter, J.R. Source level and vocalizing depth estimation of two blue whale subspecies in the western Indian Ocean from single sensor observations. J. Acoust. Soc. Am. 2021, 149, 4422-4436. [CrossRef]

25. McDonald, M.A.; Mesnick, S.L.; Hildebrand, J.A. Biogeographic characterization of blue whale song worldwide: Using song to identify populations. J. Cetacean Res. Manag. 2006, 8, 55-65. Available online: https://escholarship.org/uc/item/5r16c2mz (accessed on 14 January 2022).

26. Oleson, E.M.; Calambokidis, J.; Burgess, W.C.; McDonald, M.A.; LeDuc, C.A.; Hildebrand, J.A. Behavioral context of call production by eastern North Pacific blue whales. Mar. Ecol. Prog. Ser. 2007, 330, 269-284. [CrossRef]

27. Buchan, S.J.; Hucke-Gaete, R.; Rendell, L.; Stafford, K.M. A new song recorded from blue whales in the Corcovado Gulf, Southern Chile, and an acoustic link to the Eastern Tropical Pacific. Endanger. Species Res. 2014, 23, 241-252. [CrossRef]

28. Oleson, E.M.; Wiggins, S.M.; Hildebrand, J.A. Temporal separation of blue whale call types on a southern California feeding ground. Anim. Behav. 2007, 74, 881-894. [CrossRef]

29. Lewis, L.A.; Calambokidis, J.; Stimpert, A.K.; Fahlbusch, J.; Friedlaender, A.S.; McKenna, M.F.; Mesnick, S.L.; Oleson, E.M.; Southall, B.L.; Szesciorka, A.R. Context-dependent variability in blue whale acoustic behaviour. R. Soc. Open Sci. 2018, 5, 180241. [CrossRef] [PubMed]

30. Buchan, S.J.; Stafford, K.M.; Hucke-Gaete, R. Seasonal occurrence of southeast Pacific blue whale songs in southern Chile and the eastern tropical Pacific. Mar. Mammal Sci. 2015, 31, 440-458. [CrossRef]

31. Leroy, E.C.; Samaran, F.; Bonnel, J.; Royer, J.Y. Seasonal and diel vocalization patterns of Antarctic blue whale (Balaenoptera musculus intermedia) in the Southern Indian Ocean: A multi-year and multi-site study. PLoS ONE 2016, 11, e0163587. [CrossRef] [PubMed] 
32. Torterotot, M.; Samaran, F.; Stafford, K.M.; Royer, J.Y. Distribution of blue whale populations in the Southern Indian Ocean based on a decade of acoustic monitoring. Deep Sea Res. II 2020, 179, 104874. [CrossRef]

33. Thompson, P.O.; Findley, L.T.; Vidal, O.; Cummings, W.C. Underwater sounds of blue whales, Balaenoptera musculus, in the Gulf of California, Mexico. Mar. Mammal Sci. 1996, 12, 288-293. [CrossRef]

34. Cerchio, S.; Willson, A.; Leroy, E.C.; Muirhead, C.; Al Harthi, S.; Baldwin, R.; Cholewiak, D.; Collins, T.; Minton, G.; Rasoloarijao, T. A new blue whale song-type described for the Arabian Sea and Western Indian Ocean. Endanger. Species Res. 2020, 43, 495-515. [CrossRef]

35. Cummings, W.C.; Thompson, P.O. Underwater sounds from the blue whale, Balaenoptera musculus. J. Acoust. Soc. Am. 1971, 50, 1193-1198. [CrossRef]

36. McDonald, M.A.; Hildebrand, J.A.; Mesnick, S. Worldwide decline in tonal frequencies of blue whale songs. Endanger. Species Res. 2009, 9, 13-21. [CrossRef]

37. Gavrilov, A.N.; McCauley, R.D.; Salgado-Kent, C.; Tripovich, J.; Burton, C. Vocal characteristics of pygmy blue whales and their change over time. J. Acoust. Soc. Am. 2011, 130, 3651-3660. [CrossRef] [PubMed]

38. Gavrilov, A.N.; McCauley, R.D.; Gedamke, J. Steady inter and intra-annual decrease in the vocalization frequency of Antarctic blue whales. J. Acoust. Soc. Am. 2012, 131, 4476-4480. [CrossRef] [PubMed]

39. Miller, B.S.; Collins, K.; Barlow, J.; Calderan, S.; Leaper, R.; McDonald, M.; Ensor, P.; Olson, P.A.; Olavarria, C.; Double, M.C. Blue whale vocalizations recorded around New Zealand: 1964-2013. J. Acoust. Soc. Am. 2014, 135, 1616-1623. [CrossRef]

40. Leroy, E.C.; Royer, J.Y.; Bonnel, J.; Samaran, F. Long-term and seasonal changes of large whale call frequency in the southern Indian Ocean. J. Geophys. Res. Oceans 2018, 123, 8568-8580. [CrossRef]

41. Miksis-Olds, J.L.; Nieukirk, S.L.; Harris, D.V. Two unit analysis of Sri Lankan pygmy blue whale song over a decade. J. Acoust. Soc. Am. 2018, 144, 3618-3626. [CrossRef]

42. Malige, F.; Patris, J.; Buchan, S.J.; Stafford, K.M.; Shabangu, F.; Findlay, K.; Hucke-Gaete, R.; Neira, S.; Clark, C.W.; Glotin, H. Inter-annual decrease in pulse rate and peak frequency of Southeast Pacific blue whale song types. Sci. Rep. 2020, $10,8121$. [CrossRef]

43. Schall, E.; Di Iorio, L.; Berchok, C.; Filún, D.; Bedriñana-Romano, L.; Buchan, S.J.; Van Opzeeland, I.; Sears, R.; Hucke-Gaete, R. Visual and passive acoustic observations of blue whale trios from two distinct populations. Mar. Mammal Sci. 2019, 36, 365-374. [CrossRef]

44. Stafford, K.M.; Nieukirk, S.L.; Fox, C.G. Geographic and seasonal variation of blue whale calls in the North Pacific. J. Cetacean Res. Manag. 2001, 3, 65-76. [CrossRef]

45. Buchan, S.J.; Pérez-Santos, I.; Narváez, D.; Castro, L.; Stafford, K.M.; Baumgartner, M.F.; Valle-Levinson, A.; Montero, P.; Gutiérrez, L.; Rojas, C.; et al. Intraseasonal variation in southeast Pacific blue whale acoustic presence, zooplankton backscatter, and oceanographic variables on a feeding ground in Northern Chilean Patagonia. Prog. Oceanogr. 2021, 199, 102709. [CrossRef]

46. Stafford, K.M.; Moore, S.E.; Fox, C.G. Diel variation in blue whale calls recorded in the eastern tropical Pacific. Anim. Behav. 2005, 69, 951-958. [CrossRef]

47. Center for Conservation Bioacoustics. Raven Pro: Interactive Call Analysis Software (Version 1.6.1) [Computer Software]; The Cornell Lab of Ornithology: Ithaca, NY, USA, 2019. Available online: http://www.birds.cornell.edu/raven (accessed on 1 December 2020).

48. Charif, R.A.; Strickman, L.M.; Waack, A.M. Raven Pro 1.4 User's Manual; The Cornell Lab of Ornithology: Ithaca, NY, USA, 2010

49. Berchok, C.L.; Bradley, D.L.; Gabrielson, T.B. St. Lawrence blue whale vocalizations revisited: Characterization of calls detected from 1998 to 2001. J. Acoust. Soc. Am. 2006, 120, 2340-2354. [CrossRef] [PubMed]

50. Saddler, M.R.; Bocconcelli, A.; Hickmott, L.S.; Chiang, G.; Landea-Briones, R.; Bahamonde, P.A.; Howes, G.; Segre, P.S.; Sayigh, L.S. Characterizing Chilean blue whale vocalizations with DTAGs: A test of using tag accelerometers for caller identification. J. Exp. Biol. 2017, 220, 4119-4129. [CrossRef] [PubMed]

51. Buchan, S.J.; Gutierrez, L.; Balcazar-Cabrera, N.; Stafford, K.M. Seasonal occurrence of fin whale song off Juan Fernandez, Chile Endanger. Species Res. 2019, 39, 135-145. [CrossRef]

52. Español-Jiménez, S.; Bahamonde, P.A.; Chiang, G.; Häussermann, V. Discovering sounds in Patagonia: Characterizing sei whale (Balaenoptera borealis) downsweeps in the south-eastern Pacific Ocean. Ocean Sci. 2019, 15, 75-82. [CrossRef]

53. Dominello, T.; Širović, A. Seasonality of Antarctic minke whale (Balaenoptera bonaerensis) calls off the western Antarctic Peninsula. Mar. Mammal Sci. 2016, 32, 826-838. [CrossRef]

54. Mussoline, S.E.; Risch, D.; Hatch, L.T.; Weinrich, M.T.; Wiley, D.N.; Thompson, M.A.; Corkeron, P.J.; Van Parijs, S.M. Seasonal and diel variation in North Atlantic right whale up-calls: Implications for management and conservation in the northwestern Atlantic Ocean. Endanger. Species Res. 2012, 17, 17-26. [CrossRef]

55. Thieurmel, B.; El Mahraoui, A. suncalc: Compute Sun Position, Sunlight Phases, Moon Position and Lunar Phase, R package version 0.5.0; R Foundation for Statistical Computing: Vienna, Austria, 2019.

56. R Core Team. R: A Language and Environment for Statistical Computing; R Foundation for Statistical Computing: Vienna, Austria, 2019. Available online: https:/ / www.R-project.org/ (accessed on 14 January 2022).

57. Kruskal, W.H.; Wallis, W.A. Use of ranks in one-criterion variance analysis. J. Am. Stat. Assoc. 1952, 47, 583-621. [CrossRef]

58. Lewis, L.A.; Širović, A. Variability in blue whale acoustic behavior off southern California. Mar. Mammal Sci. 2018, 34, 311-329. [CrossRef] 
59. Matthews, J.N.; Brown, S.; Gillespie, D.; Johnson, M.; McLanaghan, R.; Moscrop, A.; Nowacek, D.; Leaper, R.; Lewis, T.; Tyack, P. Vocalisation rates of the North Atlantic right whale (Eubalaena glacialis). J. Cetacean Res. Manag. 2001, 3, $271-282$.

60. Mellinger, D.K.; Stafford, K.M.; Moore, S.E.; Dziak, R.P.; Matsumoto, H. An overview of fixed passive acoustic observation methods for cetaceans. Oceanography 2007, 20, 36-45. Available online: http://www.jstor.org/stable/24860138 (accessed on 14 January 2022). [CrossRef]

61. Baumgartner, M.F.; Mussoline, S.E. A generalized baleen whale call detection and classification system. J. Acoust. Soc. Am. 2011, 129, 2889-2902. [CrossRef] [PubMed]

62. Munger, L.M.; Wiggins, S.M.; Moore, S.E.; Hildebrand, J.A. North Pacific right whale (Eubalaena japonica) seasonal and diel calling patterns from long-term acoustic recordings in the southeastern Bering Sea, 2000-2006. Mar. Mammal Sci. 2008, 24, 795-814. [CrossRef]

63. Clark, C.W.; Brown, M.W.; Corkeron, P. Visual and acoustic surveys for North Atlantic right whales, Eubalaena glacialis, in Cape Cod Bay, Massachusetts, 2001-2005: Management implications. Mar. Mammal Sci. 2010, 26, 837-854. [CrossRef]

64. Rankin, S.; Ljungblad, D.; Clark, C.; Kato, H. Vocalisations of Antarctic blue whales, Balaenoptera musculus intermedia, recorded during the 2001/2002 and 2002/2003 IWC/SOWER circumpolar cruises, Area, V., Antarctica. J. Cetacean Res. Manag. 2005, 7, 13-20.

65. Širović, A.; Hildebrand, J.A.; Thiele, D. Baleen whale spatial patterns in the Scotia Sea during January and February 2003 J. Cetacean Res. Manag. 2006, 8, 161-171. Available online: http://hvar.is/upload/4/SFX/sfx.gif (accessed on 14 January 2022).

66. Gill, P.C.; Morrice, M.G.; Page, B.; Pirzl, R.; Levings, A.H.; Coyne, M. Blue whale habitat selection and within-season distribution in a regional upwelling system off southern Australia. Mar. Ecol. Prog. Ser. 2011, 421, 243-263. [CrossRef]

67. González, H.E.; Calderón, M.J.; Castro, L.; Clement, A.; Cuevas, L.A.; Daneri, G.; Iriarte, J.L.; Lizárraga, L.; Martínez, R.; Menschel, E. Primary production and plankton dynamics in the Reloncaví Fjord and the Interior Sea of Chiloé, Northern Patagonia, Chile. Mar. Ecol. Prog. Ser. 2010, 402, 13-30. [CrossRef]

68. Antezana, T. Diversidad y Equilibrio Ecológico en Comunidades Pelágicas; Preservación del medio ambiente marino; Instituto de Estudios Internacionales, Universidad de Chile: Santiago, Chile, 1976; pp. 40-54.

69. Croll, D.A.; Marinovic, B.; Benson, S.; Chavez, F.P.; Black, N.; Ternullo, R.; Tershy, B.R. From wind to whales: Trophic links in a coastal upwelling system. Mar. Ecol. Prog. Ser. 2005, 289, 117-130. [CrossRef]

70. Buchan, S.J.; Quiñones, R.A. First insights into the oceanographic characteristics of a blue whale feeding ground in northern Patagonia, Chile. Mar. Ecol. Prog. Ser. 2016, 554, 183-199. [CrossRef]

71. Szesciorka, A.R.; Ballance, L.T.; Širović, A.; Rice, A.; Ohman, M.D.; Hildebrand, J.A.; Franks, P.J.S. Timing is everything: Drivers of interannual variability in blue whale migration. Sci. Rep. 2020, 10, 7710. [CrossRef] [PubMed]

72. Clapham, P.J. The social and reproductive biology of humpback whales: An ecological perspective. Mammal Rev. 1996, 26, 27-49. [CrossRef]

73. Brown, M.R.; Corkeron, P.J.; Hale, P.T.; Schultz, K.W.; Bryden, M.M. Evidence for a sex-segregated migration in the humpback whale (Megaptera novaeangliae). Proc. Roy. Soc. Lond. B 1995, 259, 229-234. [CrossRef]

74. Thomisch, K.; Boebel, O.; Clark, C.W.; Hagen, W.; Spiesecke, S.; Zitterbart, D.P.; Van Opzeeland, I. Spatio-temporal patterns in acoustic presence and distribution of Antarctic blue whales Balaenoptera musculus intermedia in the Weddell Sea. Endanger. Species Res. 2016, 30, 239-253. [CrossRef]

75. Torres-Florez, J.P.; Hucke-Gaete, R.; Rosenbaum, H.; Figueroa, C.C. High genetic diversity in a small population: The case of Chilean blue whales. Ecol. Evol. 2014, 4, 1398-1412. [CrossRef]

76. Torres-Florez, J.P.; Olson, P.A.; Bedriñana-Romano, L.; Rosenbaum, H.; Ruiz, J.; LeDuc, R.; Hucke-Gaete, R. First documented migratory destination for eastern South Pacific blue whales. Mar. Mammal Sci. 2015, 31, 1580-1586. [CrossRef]

77. Croll, D.A.; Tershy, B.R.; Hewitt, R.P.; Demer, D.A.; Fiedler, P.C.; Smith, S.E.; Armstrong, W.; Popp, J.M.; Kiekhefer, T.; Lopez, V.R. An integrated approach to the foraging ecology of marine birds and mammals. Deep Sea Res. II 1998, 45, 1353-1371. [CrossRef]

78. Tyack, P. Functional aspects of cetacean communication. In Cetacean Societies: Field Studies of Dolphins and Whales; Mann, J., Ed.; University of Chicago Press: Chicago, IL, USA, 2000.

79. Mauchline, J.; Fisher, L. The biology of Euphausiids. In Advances in Marine Biology; Academic Press: Cambridge, MA, USA, 1969; Volume 7.

80. Cushing, D.H. Upwelling and the production of fish. In Advances in Marine Biology; Elsevier: Amsterdam, The Netherlands, 1971; pp. 255-334. [CrossRef]

81. Berkes, F. Some aspects of feeding mechanisms of euphausiid crustaceans. Crustaceana 1975, 29, 266-270. Available online: http:/ / www.jstor.org/stable/20102261 (accessed on 14 January 2022). [CrossRef]

82. Payne, R.; Webb, D. Orientation by means of long-range acoustic signaling in baleen whales. Ann. N. Y. Acad. Sci. 1971, 188, 110-141. [CrossRef]

83. Wiley, R.H.; Richards, D.G. Physical constraints on acoustic communication in the atmosphere: Implications for the evolution of animal vocalizations. Behav. Ecol. Sociobiol. 1978, 3, 69-94. [CrossRef]

84. Oleson, E.M.; Širović, A.; Bayless, A.R.; Hildebrand, J.A. Synchronous seasonal change in fin whale song in the North Pacific. PLoS ONE 2014, 9, e115678. [CrossRef] [PubMed]

85. McCordic, J.A.; Root-Gutteridge, H.; Cusano, D.A.; Denes, S.L.; Parks, S.E. Calls of North Atlantic right whales Eubalaena glacialis contain information on individual identity and age class. Endanger. Species Res. 2016, 30, 157-169. [CrossRef] 